\title{
Prevalence and Factors Associated with Hypertension among Adolescents in Malaysia
}

\author{
Liew JK ${ }^{a e}$, Cheong XP ${ }^{b e}$, Law $L^{a e}$, Teo $W^{c e}$, Eng SS ${ }^{d e}$, Ngim $C F^{e}$, Ramadas $A^{e}$. \\ aHospital Umum Sarawak, Jalan Hospital, 93586 Kuching, Sarawak, Malaysia. \\ bHospital Sultanah Aminah, Jalan Persiaran Abu Bakar Sultan, 80100 Johor Bahru, Johor, Malaysia. \\ 'Hospital Seberang Jaya, Jalan Tun Hussein Onn, 13700 Seberang Jaya, Pulau Pinang, Malaysia. \\ dHospital Pulau Pinang, Jalan Residensi, 10990 George Town, Pulau Pinang, Malaysia. \\ e Jeffrey Cheah School of Medicine and Health Science, Monash University Malaysia, 47500 Bandar Sunway, \\ Selangor Darul Ehsan, Malaysia.
}

\section{ABSTRACT}

Introduction: Evidence has shown an increase in paediatric hypertension globally and this could give rise to increase prevalence of adult hypertension. The purpose of this paper was to determine the prevalence of hypertension among adolescents in Malaysia as well as the association between hypertension and lifestyle factors selected based on published literature. Methods: Adolescents aged 13-17 years old were selected randomly from two secondary schools to have their blood pressure measured. Their lifestyle information was obtained through completed bilingual questionnaires based on validated instruments, as well as anthropometry measurements. The relationship between hypertension and lifestyle factors was determined through statistical analysis. Results: A total of 273 students were included in the study with 120 (44\%) males and 153 (56\%) females. The prevalence of hypertension was $24.5 \%$ among the respondents with the highest being recorded among Malays (28.7\%). Generally, hypertension was associated with an increased Body Mass Index (BMI) (AOR=4.053, 95\% Cl=1.677-9.795, $p=0.002)$ and waist circumference (WC) (AOR=2.918, $95 \% \mathrm{Cl}=1.171-7.269, p=0.021)$ in all respondents. Similar associations were noted in females (BMI: $A O R=7.707$, $95 \% \mathrm{Cl}=2.043-29.072, \mathrm{p}=0.003$; WC: $\mathrm{AOR}=3.690,95 \% \mathrm{Cl}=1.011-13.464, \mathrm{p}=0.048)$ but not in males. Conclusion: Hypertension recorded high prevalence among Malaysian adolescents in our study. The strong association between elevated body weight, BMI and WC with hypertension may require further study to evaluate the need for screening.

KEYWORDS : hypertension, adolescent, lifestyle factors, body mass index, waist circumference

\section{INTRODUCTION}

Paediatric hypertension is on the rise and commonly leads to adult hypertension. Globally, the prevalence of paediatric hypertension is reportedly around 2-5\%; this may be underreported as nearly $75 \%$ of cases were missed in the primary care setting. ${ }^{1,2}$ Studies in the United States and

Corresponding Author

Dr Amutha Ramadas

Jeffrey Cheah School of Medicine and Health

Sciences, Monash University Malaysia,

Jalan Lagoon Selatan,

47500 Bandar Sunway, Malaysia

Tel : +60355159660

Email: amutha.ramadas@monash.edu
European countries reported that only $13-26 \%$ of adolescent hypertension are properly diagnosed. ${ }^{3}$ This may be contributed by the cumbersome interpretation of blood pressure (BP) readings based on gender and age-specific charts for the paediatric age group and readings taken by inexperienced health personnel. ${ }^{3}$ If left unchecked, paediatric hypertension potentially leads to chronic adult hypertension, as BP continues to increase during growth and puberty. ${ }^{4-6}$ Recent meta-analysis show that an elevated blood pressure in childhood especially in children older than 15 years of age is likely to assist in predicting adult hypertension. ${ }^{4}$ Asian children are at higher risk of hypertension compared to other ethnicities, especially Asian males who are 4.25 times more likely to suffer hypertension by age 35 than females. ${ }^{6,7}$ The impact 
of hypertension can be detected even in childhood as $41 \%$ of adolescents with hypertension were shown to have left ventricular hypertrophy on echocardiography thus highlighting the severity of this phenomenon. ${ }^{8}$

Obesity has been widely recognized as the main culprit of hypertension in children. ${ }^{9,10}$ Since 1980, the prevalence of obesity among children has almost tripled. ${ }^{11}$ United States statistics have shown that among children aged 2-19 years old, obesity prevalence is as high as $17 \% .^{11}$ In Malaysia, the National Health and Morbidity Survey (NHMS) 2011 reported an overall obesity prevalence at $6.1 \%$ among children below the age of 18 years, an increase from $5.4 \%$ from $2006 .{ }^{12}$ International data has shown that the incidence of hypertension is about $3-14 \%$ in normal-weight children and $11-30 \%$ in obese children, in other words obese children are three times more likely to be hypertensive than their non-obese peers. ${ }^{3,13}$ However, the prevalence of hypertension among the Malaysian paediatric population has not been extensively studied in recent years. A study conducted in 2012 in the state of Sabah, Malaysia reported hypertension prevalence of $14 \%$ among children age $8-9,{ }^{14}$ while another study in year 2011 among adolescents age 13-17 in Putrajaya, Malaysia reported prehypertension and hypertension of $11.1 \%$ and $11.6 \%$ respectively. ${ }^{15}$

Multiple lifestyle factors are associated with the increased risk of obesity and hypertension in population studies. A meta-analysis found a linear dose-response association between sedentary duration and childhood obesity, with an increased risk of $13 \%$ for each hour per day spent on watching television. ${ }^{16}$ Additionally, obesity is associated with increased $\mathrm{BP}$, total cholesterol, social misbehaviour, reduced physical fitness and academic achievement. ${ }^{17}$ As for the risk of hypertension, implementing moderate-vigorous physical activity among adolescents have been shown to increase lean mass ${ }^{18}$ while increasing physical activity duration by 30 minutes and 60 minutes daily has been associated with lowering the risk of hypertension by $50 \%$ and $62 \%$ respectively. ${ }^{19}$ Unhealthy diets high in calorie, sugar and salt are linked to increased cardiometabolic disorders due to the predisposition to high BP, dyslipidaemia and diabetes. ${ }^{20}$ Sleep duration is another possible contributor to high BP, with some studies suggesting lack of sleep ( $<6 \mathrm{hr} /$ day) and excessive (>8hr/day) sleep may lead to cardiometabolic diseases. ${ }^{21}$ Lastly mental health and social support can also affect hypertension. Hypertensive patients often experience symptoms of anxiety, stress and depression ${ }^{22}$ and reported smaller social networks. ${ }^{23}$

To the best of our knowledge, our study is one of the few studies conducted on adolescent hypertension and obesity in Malaysia. This article reports the prevalence of hypertension among Malaysian adolescents and its association with obesity as well as other possible lifestyle factors reported in published literature. ${ }^{16-23}$

\section{METHODOLOGY}

This cross sectional study was conducted at two secondary schools in Johor Bahru which is the capital of the southern state of Johor, Malaysia. As one secondary school was for boys and the other catered for girls, both gender were represented in our study. Participants were students aged 13-17 years old selected randomly by the school authorities based on their availability as per the school timetable. The students' participation were voluntary with written informed consent obtained from their parents or guardians. Students who were unable to complete the questionnaire in English or Malay were excluded from the study. The study was approved by Monash Human Research Ethics Committee (MUHREC) [CF15/4035 - 2015001727], Ministry of Education Malaysia [KPMSp.600-3/2/3/ Jld30(71), and the State Education Department of Johor [JPNJ.PP(31)/100-5/3/2/Jld6].

Respondents completed a self-administered bilingual questionnaire which included information on demographic background and lifestyle habits namely their physical activities, diet, depression scores, sleep duration and duration of sedentariness. Validated survey tools such as the International Physical Activity Questionnaires (IPAQ) which has been used to screen fitness in various public health studies, was used in our study to grade the students' levels of physical fitness into the following categories: unhealthy $(M E T<3)$, moderately healthy (MET 3-6) and healthy (MET>6). ${ }^{24,25}$ The Mediterranean Diet Quality Index (KIDMED), another validated nutritional screening tool used worldwide was utilised to score their diet 
into either healthy ( $>8$ points), moderately healthy (4-7 points) or unhealthy ( $<3$ points). ${ }^{26,27}$ Lastly, the students completed the Patient Health Questionaires (PHQ-9), which is a US validated mental health screening tool, based on the DSM-IV criteria which screens for depression (>4 points)..$^{28,29}$

Anthropometry measurements including height and weight were then taken using standardised tools such as a wall-mounted stadiometer and an electronic weighing scale. BP readings were recorded using the OMRON electronic blood pressure measuring device by researchers who were final year medical students of Monash University Malaysia. Appropriate BP cuff sizes, ranging from adult to large adult cuffs were fitted to students based on the CDC recommendations of cuff bladder length covering 80-100 percent of the circumference of the arm, at a point midway between the olecranon and acromion. ${ }^{30}$ Three readings were obtained on three separate occasions from the right arm of participants seated upright after resting for five minutes and the systolic and diastolic BP was defined as the average of the three readings obtained. ${ }^{30}$

Absolute cut-off values generally used in adult population for BP, Body Mass Index (BMI) and waist circumference (WC) will not show an accurate reflection in children as there are drastic changes in both height and weight with age and their relationship to body fat percentage as they grow. Therefore, age-adjusted height percentile was calculated for each participant using gendermatched stature-for-ages tables published by the Centers for Disease Control and Prevention (CDC). ${ }^{31}$ Based on the height percentiles, BP was normally distributed into percentiles in the National High Blood Pressure Education Program (NHBPEP) Fourth Report ${ }^{31}$ which then generate appropriate BP levels for adolescents based on their age, gender and height percentiles. Based on the Fourth Report, hypertension was defined in our study as systolic BP or diastolic BP above the $95^{\text {th }}$ percentile. ${ }^{30}$

BMI was calculated based on the standard formula $\left(\mathrm{kg} / \mathrm{m}^{2}\right)$. Using $\mathrm{CDC}$ age and gender-matched nomogram, BMI values of above $85^{\text {th }}$ percentile are categorised as overweight/obese. ${ }^{32}$ WC was adjusted to South Asian figures, based on a large scale Malaysian cross sectional study, which recommends the $90^{\text {th }}$ percentile as the cut-off for determining abdominal obesity among adolescents. ${ }^{33}$ Statistical analysis was conducted with IBM SPSS Statistics 20.0 and statistical significance was set at $p<0.05$.

\section{RESULTS}

A total of 273 students participated in the study, consisting of $120(44 \%)$ males and 153 (56\%) females, with a mean age of 14.6 years ( $S D \pm 1.5$ years) (Table 1). Their ethnicities reflected those of students attending the two schools in which the majority were Chinese (41.8\%) and Malays (34.4\%). The overall prevalence of hypertension among our respondents was $24.5 \%(n=67)$. The prevalence of hypertension appeared highest among Malays (28.7\%) followed by the Indians (26.2\%) and Chinese (20.2\%). In terms of gender, hypertension was more common among males (31.7\%) compared to females $(19.0 \%)$.

Table 1 also depicts the proportion of students with and without hypertension based on their anthropometric measurements and lifestyle factors. Amongst our respondents, $23.8 \%(n=65)$ were found to be either overweight or obese with a BMI of more than $85^{\text {th }}$ percentile and in this group of students, the prevalence of hypertension was very high at $58.4 \%(38 / 65)$ as compared to $13.9 \%(29 / 208)$ in those with BMI within the normal range. The same trend was noted for abdominal obesity (defined as WC above the $90^{\text {th }}$ percentile) which was noted in $19.4 \%$ of our study population; hypertension affected $60.4 \%(32 / 53)$ of those with abdominal obesity as compared to $15.9 \%(35 / 220)$ of those without abdominal obesity. There was a significant difference observed between hypertensive and nonhypertensive respondents in terms of BMI $(p<0.001)$, waist circumference $(p<0.001)$ and gender $(p=0.023)$. Univariate logistic regression analysis (Table 2) shows hypertension to be associated with male $(\mathrm{OR}=1.981,95 \% \mathrm{Cl}=1.134-3.462, \mathrm{p}=0.016)$. Hypertension was also associated with i) higher median $\mathrm{BMI} \quad(\mathrm{OR}=1.287, \quad 95 \% \quad \mathrm{Cl}=1.193-1.387$, $\mathrm{p}<0.001)$, ii) $B M I \geq 85^{\text {th }}$ percentile $(O R=8.687,95 \%$ $\mathrm{Cl}=4.625-16.316, \quad \mathrm{p}<0.001$, ), iii) higher mean $W C$ (OR=1.102, 95\% $\mathrm{Cl}=1.070-1.135, \mathrm{p}<0.001)$ and iv) $\mathrm{WC}$ $\geq 90^{\text {th }}$ percentile $(\mathrm{OR}=8.054,95 \% \mathrm{Cl}=4.170-15.559$, $\mathrm{p}<0.001)$. Multivariate logistic regression analysis showed associations between hypertension with $\mathrm{BMI}$ $\geq 85^{\text {th }}$ percentile $(\mathrm{AOR}=4.053,95 \% \mathrm{Cl}=4.625-16.316$, $\mathrm{p}=0.002)$ and $\mathrm{WC} \geq 90^{\text {th }}$ percentile (AOR=2.918, 95\% $\mathrm{Cl}=1.171-7.269, \mathrm{p}=0.021)$. 
Table 1: Hypertension and the association with demographic and characteristics $(n=273)$

\begin{tabular}{|c|c|c|c|c|c|c|}
\hline & & & $\begin{array}{l}\text { Total } n=273 \\
n(\%)\end{array}$ & $\begin{array}{l}\text { No } \\
\text { Hypertension } \\
(\mathrm{n}=206)\end{array}$ & $\begin{array}{l}\text { Hypertension } \\
(n=67)\end{array}$ & $p$ \\
\hline \multirow{6}{*}{$\begin{array}{l}\text { Socio- } \\
\text { demography }\end{array}$} & Age & & $14.6(1.5)^{\#}$ & $14.7(1.4)^{\#}$ & $14.8(1.3)^{\#}$ & 0.501 \\
\hline & \multirow[t]{2}{*}{ Gender } & Male & $120(44.0)$ & $82(39.8)$ & $38(56.7 \%)$ & \multirow[t]{2}{*}{$0.023^{*}$} \\
\hline & & Female & $153(56.0)$ & $124(60.2 \%)$ & $29(43.3 \%)$ & \\
\hline & \multirow[t]{3}{*}{ Ethnicity } & Malay & $94(34.4)$ & $67(32.5)$ & $27(40.3)$ & \multirow[t]{3}{*}{0.341} \\
\hline & & Chinese & $114(41.8)$ & $91(44.2)$ & $23(34.3)$ & \\
\hline & & Indian & $65(23.8)$ & 48 (23.3) & $17(25.4)$ & \\
\hline \multirow{6}{*}{ Anthropometry } & BMI $\left(\mathrm{kg} / \mathrm{m}^{2}\right)$ & & $20.3(4.7)^{\wedge}$ & $19.5(3.9)^{\wedge}$ & $24.3(8.8)^{\wedge}$ & $<0.001^{* *}$ \\
\hline & \multirow[t]{2}{*}{ BMI categories } & $\geq 85^{\text {th }}$ percentile & $65(23.8)$ & $27(13.1)$ & $38(56.7)$ & \multirow[t]{2}{*}{$<0.001^{* *}$} \\
\hline & & $<85^{\text {th }}$ percentile & $208(76.2)$ & $179(86.9)$ & $29(43.3)$ & \\
\hline & $\begin{array}{l}\text { Waist } \\
\text { circumference } \\
\text { (cm) }\end{array}$ & & $75.1(11.5)^{\#}$ & $72.1(8.7)^{\#}$ & $84.3(13.9)^{\#}$ & $<0.001^{* *}$ \\
\hline & Waist & $\geq 90^{\text {th }}$ percentile & $53(19.4)$ & 21 10.2) & $32(47.8)$ & \\
\hline & $\begin{array}{l}\text { circumterence } \\
\text { categories }\end{array}$ & $<90^{\text {th }}$ percentile & $220(80.6)$ & $185(89.8)$ & $35(52.2)$ & $<0.001$ \\
\hline \multirow[t]{11}{*}{ Lifestyle } & \multirow{4}{*}{$\begin{array}{l}\text { Sleep Duration } \\
\text { (hours/day) }\end{array}$} & $\leq 5$ hours & $34(12.5)$ & $25(12.1)$ & $9(13.4)$ & \multirow[t]{4}{*}{0.364} \\
\hline & & 6 hours & $88(32.2)$ & $66(32.0))$ & $22(32.8)$ & \\
\hline & & 7 hours & $90(33.0)$ & $64(31.1)$ & $26(38.8)$ & \\
\hline & & $\geq 8$ hours & $61(22.3)$ & $51(24.8)$ & $10(14.9)$ & \\
\hline & \multirow[t]{3}{*}{$\begin{array}{l}\text { Physical } \\
\text { activity level }\end{array}$} & Low & $47(17.2)$ & $38(18.4)$ & $9(13.4)$ & \multirow[t]{3}{*}{0.171} \\
\hline & & Moderate & $140(51.3)$ & $99(48.1)$ & $41(61.2)$ & \\
\hline & & High & $86(31.5)$ & $69(33.5)$ & $17(25.4 \%)$ & \\
\hline & $\begin{array}{l}\text { Sedentariness } \\
\text { (hours/day) }\end{array}$ & & $7.3(1.9)^{\#}$ & $7.2(1.8)^{\#}$ & $7.4(2.1)^{\#}$ & 0.603 \\
\hline & \multirow[t]{3}{*}{$\begin{array}{l}\text { Diet Quality } \\
\text { (KIDMED) }\end{array}$} & Poor & $88(32.2)$ & $67(32.5)$ & $21(31.3)$ & \multirow[t]{3}{*}{0.760} \\
\hline & & Moderate & $166(60.8)$ & $126(61.2)$ & $40(59.7)$ & \\
\hline & & High (Optimal) & $19(7.0)$ & $13(6.3)$ & $6(9.0)$ & \\
\hline Depression & \multicolumn{2}{|l|}{ PHQ index } & $15(6)^{\wedge}$ & $15(5)^{\wedge}$ & $14(7)^{\wedge}$ & 0.121 \\
\hline
\end{tabular}

\# mean (SD) for normally distributed data, "median (IQR) for skewed distribution and $\mathrm{n}(\%)$ for categorical variables. Comparison of continuous variables were done using Independent t-test or Mann Whitney $U$, and of categorical variables were done with chi-square or Fisher's Exact test. *significant at $p<0.05$; **significant at $p<0.001$

Simple and multivariable logistic regression was conducted in the male and female subgroups to study the association between hypertension and the factors described earlier (Tables 3 and 4). Among the males (Table 3), it was found that all independent variables including socio-demographic, anthropometric and lifestyle factors were not associated with the occurrence of hypertension. Instead, among the females (Table 4), hypertension was significantly associated with $\mathrm{BMI}$ $\geq 85^{\text {th }}$ percentile $(A O R=7.707,95 \% \quad \mathrm{Cl}=2.043-29.072$, $\mathrm{p}=0.003)$ and $\mathrm{WC} \geq 90^{\text {th }}$ percentile $(A O R=3.690,95 \%$ $\mathrm{Cl}=1.011-13.464, \mathrm{p}=0.048)$.

\section{DISCUSSION}

Our study revealed that the prevalence of hypertension and overweight/obesity among Malaysian adolescents were indeed high at $24.5 \%$ and $23.8 \%$ respectively. Hypertension appeared to be strongly associated to higher BMI, abdominal obesity (WC) and to a certain extent the male gender. However, no association was found between hypertension and other lifestyle factors including sleep duration, physical activity level, sedentariness, diet quality and depression scores. In terms of ethnicity distribution, we found the 
prevalence of hypertension to be highest amongst Malay students compared to other ethnic groups although the difference was not statistically significant. This was in spite of Chinese being the largest ethnic group in our cohort sample. The difference can be explained by NHMS statistics which noted that Malays have always been the biggest group with HPT (33.9\% in 2006 and 34\% in 2011). ${ }^{34}$

The prevalence of hypertension found in our study (24.5\%) was higher than the reported prevalence of $11.7 \%$ in adolescents in another urban city in Malaysia. ${ }^{15}$ It was noted in the study by Rampal et al that $11.7 \%$ of the subjects were overweight (none classified as obese) whereas in our study, a much higher prevalence of overweight/obesity was found (23.8\%) which may explained the higher prevalence of hypertension in our study population. ${ }^{15}$

Indeed, our reported figures on prevalence of obesity in Malaysian adolescents mirrors the recent statistics from the Malaysian Association for the Study of Obesity (MASO) which found 19\% of adolescents (aged 12-17 years) across various Malaysian states to be overweight according to WHO definition of BMI-for-age cut-off $>85^{\text {th }}$ percentile. ${ }^{35}$ This is even higher than other South East Asian countries such as Thailand (7.6\%) and Phillipines $(4.8 \%)$, almost mirroring the obesity prevalence of UK (11\%) and US (35\%). ${ }^{9}$ Although nationwide statistic on BMI in adolescent is available, there appeared to be a gap in terms of data on hypertension that will be valuable in the light of new evidence especially in the face of rising obesity.

Table 2: Simple and multivariable logistic regression between independent variables and hypertension status of all respondents $(n=273)$

\begin{tabular}{|c|c|c|c|c|c|c|c|c|}
\hline & & & OR & $95 \% \mathrm{Cl}$ & $P$ & $\mathrm{AOR}^{\mathrm{a}}$ & $95 \% \mathrm{Cl}$ & $p$ \\
\hline \multirow[t]{6}{*}{$\begin{array}{l}\text { Socio- } \\
\text { demography }\end{array}$} & Age & & 1.071 & $0.877-1.309$ & 0.499 & & & \\
\hline & \multirow[t]{2}{*}{ Gender } & Male & 1.981 & $1.134-3.462$ & $0.016^{*}$ & 1.402 & $0.731-2.688$ & 0.310 \\
\hline & & Female & 1.000 & & & & & \\
\hline & \multirow[t]{3}{*}{ Ethnicity } & Malay & 1.594 & $0.841-3.022$ & 0.153 & & & \\
\hline & & Indian & 1.401 & $0.684-2.872$ & 0.357 & & & \\
\hline & & Chinese & 1.000 & & & & & \\
\hline \multirow[t]{6}{*}{ Anthropometry } & BMI $\left(\mathrm{kg} / \mathrm{m}^{2}\right)$ & & 1.287 & $1.193-1.387$ & $<0.001^{* *}$ & & & \\
\hline & \multirow[t]{2}{*}{ BMI categories } & \multirow{3}{*}{$\begin{array}{l}\geq 85^{\text {th }} \\
\text { percentile } \\
<85^{\text {th }} \\
\text { percentile }\end{array}$} & 8.687 & $4.625-16.316$ & $<0.001^{* *}$ & 4.053 & $1.677-9.795$ & $0.002^{*}$ \\
\hline & & & 1.000 & & & & & \\
\hline & $\begin{array}{l}\text { Waist } \\
\text { circumference } \\
(\mathrm{cm})\end{array}$ & & 1.102 & $1.070-1.135$ & $<0.001^{* *}$ & & & \\
\hline & $\begin{array}{l}\text { Waist } \\
\text { circumference } \\
\text { categories }\end{array}$ & $\begin{array}{l}\geq 90^{\text {th }} \\
\text { percentile }\end{array}$ & 8.054 & $4.170-15.559$ & $<0.001^{* *}$ & 2.918 & $1.171-7.269$ & $0.021^{*}$ \\
\hline & & $\begin{array}{l}<90^{\text {th }} \\
\text { percentile }\end{array}$ & 1.000 & & & & & \\
\hline \multirow[t]{11}{*}{ Lifestyle } & \multirow{4}{*}{$\begin{array}{l}\text { Sleep duration } \\
\text { (hours/day) }\end{array}$} & & 1.836 & $0.662-5.090$ & 0.243 & & & \\
\hline & & 6 & 1.700 & $0.740-3.907$ & 0.211 & & & \\
\hline & & $\underline{7}$ & 2.072 & $0.915-4.689$ & 0.080 & & & \\
\hline & & $\geq 8$ & 1.000 & & & & & \\
\hline & \multirow{3}{*}{$\begin{array}{l}\text { Physical activity } \\
\text { level }\end{array}$} & Low & 0.961 & $0.391-2.364$ & 0.391 & & & \\
\hline & & Moderate & 1.681 & $0.883-3.199$ & 0.114 & & & \\
\hline & & High & 1.000 & & & & & \\
\hline & \multirow{4}{*}{$\begin{array}{l}\text { Sedentariness } \\
\text { (hours/day) } \\
\text { Diet Quality } \\
\text { (KIDMED) }\end{array}$} & & 1.040 & $0.898-1.205$ & 0.601 & & & \\
\hline & & Poor & 0.679 & $0.230-2.009$ & 0.484 & & & \\
\hline & & Moderate & 0.688 & $0.245-1.928$ & 0.477 & & & \\
\hline & & High & 1.000 & & & & & \\
\hline Depression & PHQ index & & 0.971 & $0.908-1.038$ & 0.384 & & & \\
\hline
\end{tabular}


Table 3 : Simple and multivariable logistic regression between independent variables and hypertension status of males $(n=120)$

\begin{tabular}{|c|c|c|c|c|c|c|c|c|}
\hline & & & OR & $95 \% \mathrm{Cl}$ & $P$ & $\mathrm{AOR}^{\mathrm{a}}$ & $95 \% \mathrm{Cl}$ & $P$ \\
\hline \multirow{4}{*}{$\begin{array}{l}\text { Socio- } \\
\text { demography }\end{array}$} & Age & & 1.287 & $0.970-1.708$ & 0.080 & 1.148 & $0.804-1.639$ & 0.446 \\
\hline & Ethnicity & Malay & 1.286 & $0.472-3.499$ & 0.623 & & & \\
\hline & & Indian & 1.125 & $0.324-3.909$ & 0.853 & & & \\
\hline & & Chinese & 1.000 & & & & & \\
\hline \multirow[t]{6}{*}{ Anthropometry } & BMI $\left(\mathrm{kg} / \mathrm{m}^{2}\right)$ & & 1.192 & $1.095-1.298$ & $<0.001$ & & & \\
\hline & $\begin{array}{l}\text { BMI } \\
\text { categories }\end{array}$ & $\begin{array}{l}>85 \text { th } \\
\text { percentile }\end{array}$ & 4.753 & $2.087-10.824$ & $<0.001$ & 2.620 & $0.738-9.306$ & 0.136 \\
\hline & & $\begin{array}{l}\leq 85 \text { th } \\
\text { percentile }\end{array}$ & 1.000 & & & & & \\
\hline & $\begin{array}{l}\text { Waist } \\
\text { circumference } \\
\text { (cm) }\end{array}$ & & 1.070 & $1.034-1.106$ & $<0.001$ & & & \\
\hline & $\begin{array}{l}\text { Waist } \\
\text { circumference }\end{array}$ & $\begin{array}{l}>90 \text { th } \\
\text { Percentile }\end{array}$ & 5.225 & $2.122-12.868$ & $<0.001$ & 2.628 & $0.633-10.913$ & 0.183 \\
\hline & categories & $\begin{array}{l}<90 \text { th } \\
\text { percentile }\end{array}$ & 1.000 & & & & & \\
\hline \multirow[t]{11}{*}{ Lifestyle } & $\begin{array}{l}\text { Sleep duration } \\
\text { (hours/day) }\end{array}$ & $\leq 5$ & 4.107 & $0.860-19.613$ & 0.077 & 4.063 & $0.648-25.483$ & 0.135 \\
\hline & & 6 & 2.875 & $0.821-10.067$ & 0.099 & 2.616 & $0.556-12.321$ & 0.224 \\
\hline & & 7 & 3.538 & $1.033-12.117$ & 0.044 & 3.232 & $0.8120-12.892$ & 0.097 \\
\hline & & $\geq 8$ & 1.000 & & & 1.000 & & \\
\hline & $\begin{array}{l}\text { Physical } \\
\text { activity level }\end{array}$ & Low & 3.200 & $0.583-17.553$ & 0.180 & 2.137 & $0.282-16.198$ & 0.463 \\
\hline & & Moderate & 2.065 & $0.921-4.629$ & 0.079 & 1.902 & $0.767-4.717$ & 0.165 \\
\hline & & High & 1.000 & & & 1.000 & & \\
\hline & $\begin{array}{l}\text { Sedentariness } \\
\text { (hours/day) }\end{array}$ & & 0.979 & $0.815-1.175$ & 0.816 & & & \\
\hline & $\begin{array}{l}\text { Diet Quality } \\
\text { (KIDMED) }\end{array}$ & Poor & 0.171 & $0.028-1.046$ & 0.056 & & & \\
\hline & & Moderate & 0.250 & $0.042-1.477$ & 0.126 & & & \\
\hline & & $\begin{array}{l}\text { High } \\
\text { (optimal) }\end{array}$ & 1.000 & & & & & \\
\hline Depression & PHQ index & & 0.996 & 0.904-1.099 & 0.943 & & & \\
\hline
\end{tabular}

$\mathrm{OR}=$ crude odds ratio; $\mathrm{AOR}=$ adjusted odds ratio with Hypertension $=1$, Normotensive $=0$

${ }^{a}$ Multivariable logistic regression was conducted. Independent variables with $p<0.20$ were entered into the model. All assumptions were met.

*significant at $p<0.05 ;{ }^{* *}$ significant at $p<0.001$

The association between hypertension and weight or BMI has been elucidated in various literature. The biological mechanism that causes hypertension in overweight adolescents remained uncertain although the role of biochemically-rich hormones namely leptin, adiponectin and osteonectin in adipose tissues, insulin, renin and aldosterone have been postulated to play a role. ${ }^{36}$ Moreover, generalised obesity (defined based on the BMI) and abdominal obesity (defined using age-adjusted WC >90th percentile) showed cumulative effect when combined to evaluate adolescent cardiometabolic risk. ${ }^{37}$ Although generalised obesity on its own only showed strong association with elevated triglyceride but in combination with abdominal obesity, a stronger association with BP, triglyceride and total cholesterol is shown thus underlining the importance of waist circumference measurements in assessing these adolescents. ${ }^{38}$ 
Meanwhile, gender differences and the risk of hypertension may be explained by differences in hormonal structures and behavioural practice between males and females. From adolescence up to 65 years old, the risk of hypertension in females is five times lesser due to protective factors from their sex hormones such as estrogen and progesterone. $^{39}$ Women also reportedly have healthier weights compared to men and are less likely to be smokers according to a national US study. ${ }^{38}$ In our study however, the initial association found on univariate analysis between male and hypertension was lost after adjusting for confounding variables. This may be due to our small sample size and the disparity in sample size between genders in our cohort. Another interesting finding in our subgroup analysis was the association between $\mathrm{BMI}>85^{\text {th }}$ percentile and $\mathrm{WC}>90^{\text {th }}$ percentile with female gender which is not observed in male adolescents. This is in contrast with another study which found that weight has a greater correlation with $\mathrm{BP}$ in boys rather than girls. ${ }^{39}$ Again, we do not exclude the possibilty that this result may be due to our small sample size which remained a limitation of our study.

Table 4 : Simple and multivariable logistic regression between independent variables and hypertension status of females $(n=153)$

\begin{tabular}{|c|c|c|c|c|c|c|c|c|}
\hline & & & OR & $95 \% \mathrm{Cl}$ & $P$ & $\mathrm{AOR}^{\mathrm{a}}$ & $95 \% \mathrm{Cl}$ & $P$ \\
\hline \multirow{4}{*}{$\begin{array}{l}\text { Socio- } \\
\text { demography }\end{array}$} & Age & & 0.867 & $0.640-1.174$ & 0.356 & & & \\
\hline & \multirow[t]{3}{*}{ Ethnicity } & Malay & 0.720 & $0.190-2.730$ & 0.630 & & & \\
\hline & & Indian & 1.426 & $0.584-3.481$ & 0.436 & & & \\
\hline & & Chinese & 1.000 & & & & & \\
\hline \multirow[t]{6}{*}{ Anthropometry } & BMI $\left(\mathrm{kg} / \mathrm{m}^{2}\right)$ & & 1.484 & $1.266-1.739$ & $<0.001^{* *}$ & & & \\
\hline & \multirow[t]{2}{*}{ BMI categories } & \multirow{3}{*}{$\begin{array}{l}>85^{\text {th }} \\
\text { percentile } \\
\leq 85^{\text {th }} \\
\text { percentile }\end{array}$} & 17.908 & $6.238-51.409$ & $<0.001^{* *}$ & 7.707 & $2.043-29.072$ & $0.003^{*}$ \\
\hline & & & 1.000 & & & 1.000 & & \\
\hline & \multirow{3}{*}{$\begin{array}{l}\text { Waist } \\
\text { circumference } \\
\text { (cm) } \\
\text { Waist } \\
\text { circumference } \\
\text { categories }\end{array}$} & & 1.168 & $1.098-1.242$ & $<0.001^{* *}$ & & & \\
\hline & & $\begin{array}{l}>90^{\text {th }} \\
\text { percentile }\end{array}$ & 12.214 & $4.613-32.344$ & $<0.001^{* *}$ & 3.690 & $1.011-13.464$ & $0.048^{*}$ \\
\hline & & $\begin{array}{l}<90^{\text {th }} \\
\text { percentile }\end{array}$ & 1.000 & & & 1.000 & & \\
\hline \multirow[t]{11}{*}{ Lifestyle } & \multirow{4}{*}{$\begin{array}{l}\text { Sleep duration } \\
\text { (hours/day) }\end{array}$} & $\leq 5$ & 1.037 & $0.257-4.192$ & 0.959 & & & \\
\hline & & 6 & 1.050 & $0.336-3.284$ & 0.933 & & & \\
\hline & & 7 & 1.228 & $0.399-3.778$ & 0.720 & & & \\
\hline & & $\geq 8$ & 1.000 & & & & & \\
\hline & \multirow{3}{*}{$\begin{array}{l}\text { Physical activity } \\
\text { level }\end{array}$} & Low & 1.800 & $0.332-9.748$ & 0.495 & & & \\
\hline & & Moderate & 3.243 & $0.702-14.985$ & 0.132 & & & \\
\hline & & High & 1.000 & & & & & \\
\hline & \multirow{4}{*}{$\begin{array}{l}\text { Sedentariness } \\
\text { (hours/day) } \\
\text { Diet Quality } \\
\text { (KIDMED) }\end{array}$} & & 1.242 & $0.964-1.599$ & 0.093 & 1.195 & $0.884-1.615$ & 0.246 \\
\hline & & Poor & 1.517 & $0.278-8.287$ & 0.630 & & & \\
\hline & & Moderate & 1.244 & $0.255-6.081$ & 0.787 & & & \\
\hline & & $\begin{array}{l}\text { High } \\
\text { (optimal) }\end{array}$ & 1.000 & & & & & \\
\hline Depression & PHQ index & & 0.956 & 0.859-1.052 & 0.356 & & & \\
\hline
\end{tabular}

$\mathrm{OR}=$ crude odds ratio; $\mathrm{AOR}=$ adjusted odds ratio with Hypertension $=1$, Normotensive $=0$

a Multivariable logistic regression was conducted. Independent variables with $p<0.20$ were entered into the model.

All assumptions were met.

*significant at $p<0.05 ;{ }^{* *}$ significant at $p<0.001$ 


\section{REFERENCES}

1. Monesha A. Childhood hypertension: a review. J Hypertens 2013; 2:128

2. Hansen M, Gunn P, Kaelber D. Underdiagnosis of hypertension in children and adolescents. JAMA 2007; 298:874.

3. Ewald D, Haldeman L. Risk factors in adolescent hypertension. Glob Pediatr Health 2016; 3:2333794X1562515.

4. Chen X, Wang Y. Tracking of blood pressure from childhood to adulthood: a systematic review and meta-regression analysis. Circulation 2008; 117:3171-80.

5. Carrico R, Sun S, Sima A, Rosner B. The predictive value of childhood blood pressure values for adult elevated blood pressure. Open J Pediatr. 2013; 3: 116-26.

6. Lurbe E. Childhood blood pressure. Hypertension. 2013; 62(2):242-3.

7. Liu K, Levinson S. Comparisons of blood pressure between Asian-American children and children from other racial groups in Chicago. Public Health Rep. 1996; 111: 65-67.

8. Hanevold C, Waller J, Daniels S, Portman R, Sorof J. The effects of obesity, gender, and ethnic group on left ventricular hypertrophy and geometry in hypertensive children: a collaborative study of the International Pediatric Hypertension Association. Pediatrics 2004; 113(2):328-33.

9. Hazreen M, Su T, Jalaludin M, Dahlui M, et al. An exploratory study on risk factors for chronic non-communicable diseases among adolescents in Malaysia: overview of the Malaysian Health and Adolescents Longitudinal Research Team study (The MyHeART study). BMC Public Health 2014;14: S6.

10. Tirosh A, Shai I, Afek A, et al. Adolescent BMI trajectory and risk of diabetes versus coronary disease. N Engl J Med. 2011; 364:1315-25.

11. Brady T. Obesity-related hypertension in children. Front Pediatr. 2017; 5:197.

12. Institute for Public Health, Ministry of Health Malaysia. National Health and Morbidity Survey: Non-communicable diseases, risk factors and other health problems.

13. Anyaegbu E, Dharnidharka V. Hypertension in the teenager. Pediatr Clin North Am. 2014; 61:131-1.

14. Sreeramareddy C, Yap S, Chew W, Poulsaeman $\mathrm{V}$, Boo N, Choo K. Blood pressure and its associated factors among primary school children in suburban Selangor, Malaysia: a cross-sectional survey. J Family Community Med. 2013; 20:907.

15. Rampal L, Ng K, Nur Izzati I, et al. Prevalence of hypertension among Malay adolescents in Putrajaya secondary schools, Malaysia. Malaysian Journal of Medicine and Health Sciences 2011; 7:53-60.

16. Zhang G, Wu L, Zhou L, Lu W, Mao C. Television watching and risk of childhood obesity: a metaanalysis. Eur J Public Health.2016; 26:13-8.

17. Rezende L, Rodrigues Lopes M, Rey-López J, Matsudo $V$, Luiz 0 . Sedentary behavior and health outcomes: an overview of systematic reviews. PLOS ONE 2014; 9: 105620.

18. Ramires $V$, Dumith $S$, Wehrmeister $F$, et al. Physical activity throughout adolescence and body composition at 18 years: 1993 Pelotas (Brazil) birth cohort study. Int J Behav Nutr Phys Act. 2016; 13.

19. Mark A, Janssen I. Dose-response relation between physical activity and blood pressure in youth. Med Sci Sports Exerc. 2008; 40:1007-12.

20. Bahadoran Z, Mirmiran P, Azizi F. Fast food pattern and cardiometabolic disorders: a review of current studies. Health Promot Perspect. 2016; 5:231-40.

21. Knutson K. Sleep duration and cardiometabolic risk: a review of the epidemiologic evidence. Best Pract Res Clin Endocrinol Metab. 2010; 24:731-43.

22. Kretchy I, Owusu-Daaku F, Danquah S. Mental health in hypertension: assessing symptoms of anxiety, depression and stress on antihypertensive medication adherence. Int J Ment Health Syst. 2014; 8:25.

23. Cornwell E, Waite L. Social network resources and management of hypertension. J Health Soc Behav. 2012; 53:215-31.

24. Hagströmer M, Bergman P, De Bourdeaudhuij I, et al. Concurrent validity of a modified version of the International Physical Activity Questionnaire (IPAQ-A) in European adolescents: the HELENA Study. Int J Obes (Lond). 2008; 32: S42-8.

25. Patterson E. IPAQ scoring protocol - International Physical Activity Questionnaire.

26. Sahingoz S, Sanlier N. Compliance with Mediterranean Diet Quality Index (KIDMED) and nutrition knowledge levels in adolescents. A case study from Turkey. Appetite 2011; 57:272-7.

27. Mariscal-Arcas M, Rivas A, Velasco J, et al. Eval- 
uation of the Mediterranean Diet Quality Index (KIDMED) in children and adolescents in Southern Spain. Public Health Nutr. 2009; 12:1408.

28. Kroenke K, Spitzer R. The PHQ-9: a new depression diagnostic and severity measure. Psychiatric Annals 2002; 32:509-15.

29. Pfizer Inc. Patient Health Questionnaire. In: SAMHSA-HRSA Center for Integrated Health Solutions.

30. National High Blood Pressure Education Program Working Group on High Blood Pressure in Children and Adolescents. The fourth report on the diagnosis, evaluation, and treatment of high blood pressure in children and adolescents.

31. Centers for Disease Control and Prevention. Growth Charts - Clinical Growth Charts.

32. Centers for Disease Control and Prevention. CDC - Recommended BMI-for-age cutoffs - BMI for Age training course - DNPAO.

33. Poh B, Jannah A, Chong L, Ruzita A, Ismail M, McCarthy D. Waist circumference percentile curves for Malaysian children and adolescents aged 6.0-16.9 years. Int J Pediatr Obes. 2011; 6:229-35.

34. Naing C, Yeoh P, Wai V, et al. Hypertension in Malaysia. Medicine (Baltimore).2016; 95:2417.

35. Malaysian Association for the Study of Obesity (MASO). Strategy for the prevention of childhood obesity. In: Malaysian Association for the Study of Obesity.

36. Juonala M., Kelly R, Magnussen C, Sabin M, Cheung $M$. Development of hypertension in overweight adolescents: a review. Adolesc Health Med Ther. 2015; 6:171-81.

37. Ataie-Jafari A, Heshmat R, Kelishadi R, et al. Generalized or abdominal obesity: which one better identifies cardiometabolic risk factors among children and adolescents? The CASPIAN III Study. J Trop Pediatr. 2014; 60:377-85.

38. Everett B, Zajacova A. Gender differences in hypertension and hypertension awareness among young adults. Biodemography $\mathrm{Soc} \mathrm{Bi}-$ ol.2015; 61:1-17.

39. Ewald D, Bond S, Haldeman L. Hypertension in low-income adolescents. Glob Pediatr Health. 2017; 4:2333794X1774181. 
